\title{
A entrada na agenda brasileira do Projeto Nacional de Saneamento Rural (1985)
}

Nathalia Roland 1

Léo Heller 2

Sonaly Rezende 1

1 Universidade Federal de Minas Gerais / Programa de Pós-Graduação em Saneamento, Meio Ambiente e Recursos Hídricos, Belo Horizonte / MG - Brasil

${ }^{2}$ Fundação Oswaldo Cruz / Instituto René Rachou, Belo Horizonte / MG - Brasil

O presente artigo busca compreender as circunstâncias que culminaram na formulação e implementação, na década de 1980, do Projeto Nacional de Saneamento Rural (PNSR), adotando como marco teórico o Modelo de Múltiplos Fluxos. Os resultados evidenciam que sua ascensão à agenda governamental é decorrente de uma conjuntura marcada por intensas transições, que contribuíram para a abertura de uma janela de oportunidades. A busca pela garantia de direitos sociais no processo de redemocratização brasileiro; a atuação de movimentos sociais, como o movimento sanitarista; o grande déficit sanitário e suas consequências na saúde pública; o envolvimento conjunto de instituições com expertise, como o Instituto de Planejamento Econômico e Social (IPEA), a Fundação Serviço Especial de Saúde Pública (FSESP) e a Organização Pan-Americana de Saúde (OPAS) e a disponibilidade de recursos financeiros, provenientes de parceria com o Banco Internacional para Reconstrução e Desenvolvimento (BIRD), proporcionaram um ambiente favorável para a elaboração do PNSR.

Palavras-chave: formação da agenda; modelo de múltiplos fluxos; PNSR; política pública; saneamento rural.

\section{Inclusión en la agenda brasileña del Proyecto Nacional de Abastecimiento de Agua y Saneamiento Rural (1985)}

Este documento tiene como objetivo comprender las circunstancias que condujeron a la formulación e implementación, en la década de 1980, del Proyecto Nacional de Abastecimiento de Agua y Saneamiento Rural (PNSR), adoptando como marco teórico el modelo de flujos múltiples. Los resultados muestran que su ascenso a la agenda del gobierno se debe a una coyuntura marcada por intensas transiciones, que contribuyeron a la apertura de una ventana de oportunidad. La búsqueda de la garantía de los derechos sociales en el proceso de redemocratización brasileña; el desempeño de movimientos sociales, como el movimiento sanitario; el gran déficit de saneamiento y sus consecuencias en la salud pública; la participación conjunta de instituciones con experiencia, como el Instituto de Planificación Económica y Social (IPEA), la Fundación del Servicio Especial de Salud Pública (FSESP) y la Organización Panamericana de la Salud (OPS), y la disponibilidad de recursos financieros de una asociación con el Banco Internacional de Reconstrucción y Fomento (BIRF) proporcionó un entorno favorable para la elaboración del PNSR.

Palabras clave: formación de la agenda; modelo de flujos múltiples; PNSR; política pública; saneamiento rural.

\section{Access to the Brazilian agenda of the National Rural Water Supply and Sanitation Project (1985)}

This article seeks to understand the circumstances that culminated in the formulation and implementation of the National Rural Water Supply and Sanitation Project (PNSR) in the 1980s, using the Multiple Streams Model as its theoretical reference. The results show that the theme's ascension to the government agenda stemmed from a conjuncture marked by intense transitions that contributed to opening a policy window. The struggle to guarantee social rights in the Brazilian re-democratization process; the activities of social movements like the grassroots public health movement; the large sanitary deficit and its consequences for public health; the joint involvement of institutions with considerable expertise like Economic and Social Planning Institute (IPEA), Public Health Special Service Foundation (FSESP) and Pan-American Health Organization (PAHO) and the availability of financial resources stemming from a partnership arrangement with the International Bank for Reconstruction and Development (IBRD) provided a favorable environment for the elaboration of the PNSR.

Keywords: agenda-setting; multiple streams model; PNSR; public policy; rural water supply and sanitation. 


\section{AGRADECIMENTOS}

Os autores agradecem à Fundação de Amparo à Pesquisa do Estado de Minas Gerais (FAPEMIG) pela bolsa de doutorado concedida à primeira autora, à Coordenação de Aperfeiçoamento de Pessoal de Nível Superior (CAPES) e ao Conselho Nacional de Desenvolvimento Científico e Tecnológico (CNPq).

\section{INTRODUÇÃO}

O saneamento básico nas áreas rurais do Brasil não tem sido objeto de atuação sistemática e permanente por parte do poder público. Há forte dispersão de ações em uma multiplicidade de órgãos e ministérios, que atuam no setor de forma descoordenada, bem como ausência de planejamento de longo prazo. Sendo assim, há uma demanda histórica em incluir o saneamento básico nas áreas rurais na agenda pública.

A lei brasileira que estabelece as diretrizes nacionais para o saneamento básico apresenta a equidade e a universalização dos serviços como integrantes de seus princípios fundamentais (Lei n. 11.445, 2007). No entanto, os investimentos em ações de saneamento no País foram priorizados em centros urbanos (Rezende \& Heller, 2008), contribuindo para a geração e perpetuação de um elevado déficit nas áreas rurais. O quadro atual de atendimento por serviços de saneamento básico nas áreas rurais evidencia a incipiência das políticas públicas desenvolvidas no setor e a necessidade de maior atuação e investimentos nessas áreas. Os dados do último Censo Demográfico brasileiro (Instituto Brasileiro de Geografia e Estatística [IBGE], 2011), do ano de 2010, relativos aos domicílios situados nas áreas rurais do País, revelam que 37\% deles não possuem canalização interna para o abastecimento de água, 64\% dispõem as águas residuárias em fossas rudimentares e $11 \%$ diretamente no ambiente.

Essa não é uma exclusividade brasileira. Embora mundialmente a diferença de cobertura com serviços de abastecimento de água e esgotamento sanitário entre as áreas urbanas e rurais tenha diminuído nos últimos anos, a inequidade ainda persiste. Oito em cada dez pessoas sem acesso aos serviços básicos de abastecimento de água encontram-se nas áreas rurais. Aproximadamente metade delas vive em países subdesenvolvidos. No que se refere ao esgotamento sanitário, sete em cada dez pessoas sem acesso aos serviços encontram-se nas áreas rurais. Cerca de um terço delas vivem em países subdesenvolvidos (Joint Monitoring Programme [JMP], 2019). Para superar esse cenário é necessário o desenvolvimento de políticas públicas setoriais efetivas.

Atualmente o Brasil vivencia um importante momento em suas políticas de saneamento rural, caracterizado pela formulação do Programa Nacional de Saneamento Rural (Fundação Nacional de Saúde [FUNASA], 2019), sob coordenação da Fundação Nacional de Saúde (Funasa). Sabe-se que a análise das principais políticas públicas previamente desenvolvidas auxilia na elaboração de políticas mais efetivas, uma vez que este tipo de estudo possibilita a apreensão dos avanços realizados e dificuldades vivenciadas. De acordo com Hall (1993), trata-se de um processo de aprendizagem política em que os gestores públicos tentam compreender por que certas iniciativas podem ter alcançado êxito e por que outras falharam.

O desenvolvimento do Projeto Nacional de Saneamento Rural (PNSR), no período de 1985 a 1989, constituiu-se em uma das primeiras iniciativas em nível nacional para o planejamento da 
atuação em saneamento rural no Brasil. O Projeto foi coordenado pelo Comitê Interministerial de Saneamento Rural, composto pelo Ministério da Saúde, Ministério de Desenvolvimento Urbano e Meio Ambiente e Instituto de Planejamento Econômico e Social (IPEA), este último, designado como executor do Projeto pela Secretaria de Planejamento da Presidência da República (SEPLAN). A Organização Pan-Americana de Saúde (OPAS/OMS) promoveu assessoria técnica durante a formulação do PNSR, por meio de seus consultores nacionais e internacionais, e o Banco Internacional para a Reconstrução e Desenvolvimento (BIRD), instituição que integra o Grupo Banco Mundial, foi responsável pelo financiamento parcial do Projeto, por meio de empréstimo ao governo brasileiro.

Quanto à sua abrangência, o PNSR era subdividido em Componente Nacional e Projeto-Piloto (Instituto de Planejamento Econômico e Social [IPEA], 1985). Ao Componente Nacional coube a realização de estudos e assistência técnica de forma a auxiliar o Governo Federal na definição de políticas públicas e na preparação de um programa decenal de saneamento básico para o meio rural. O Projeto-Piloto, inicialmente previsto para ser conduzido no estado do Rio Grande do Sul, foi transferido para Minas Gerais. Intencionava-se a expansão dos projetos na esfera estadual, fornecendo um importante subsídio ao componente nacional. Assim, almejava-se com o desenvolvimento do PNSR a "realização de um trabalho de base que possa lançar raízes para uma ação permanente e duradoura" (IPEA, 1989, p. 11).

Em 1989, como resultado dos estudos que constituíram o componente nacional do Projeto, foi publicada a "Série Saneamento Rural", pelo IPEA, composta por nove volumes. Esses documentos expressam a concepção do PNSR para o desenvolvimento do saneamento rural no Brasil. Os estudos abarcavam aspectos relacionados ao planejamento e formulação de políticas públicas de saneamento rural nos três níveis de governo, abordando temas como gestão, educação, participação social, tecnologias apropriadas, recursos humanos e financeiros.

O Projeto-Piloto do (PPNSR) foi iniciado em 1987 e conduzido pela Companhia de Saneamento de Minas Gerais (Copasa). O piloto teve como meta atender 230 comunidades rurais, com populações variando entre 200 e 2.000 habitantes, com serviços de abastecimento de água, esgotamento sanitário e melhorias sanitárias domiciliares. O PPNSR foi oficialmente encerrado pela Copasa em 1994, tendo atendido a 136 comunidades rurais (Dias, 1994).

Acredita-se que a análise da conjuntura na qual se desenvolveu o PNSR traz elementos que permitem avançar na compreensão dos problemas historicamente enfrentados e das realizações alcançadas, contribuindo para a construção da atual política de saneamento rural no Brasil. Barnes, Roser, e Brown (2011), ao avaliarem processos de planejamento para o abastecimento de água e o esgotamento sanitário em áreas rurais, concluem que a avaliação de esforços passados auxilia no reconhecimento da necessidade e dos benefícios de novas práticas e promove novos processos de planejamento. O PNSR representou um importante processo de planejamento, na esfera federal, para o atendimento de comunidades rurais com serviços de saneamento básico. Trata-se de um projeto que envolveu diversos atores, nacionais e internacionais, promoveu a geração de conteúdo para o setor durante os anos de seu desenvolvimento, porém não teve continuidade. A implementação do PNSR se limitou à execução do Projeto-Piloto em Minas Gerais, não se expandindo pelo País. A descontinuidade político-administrativa é identificada em estudos como 
um empecilho ao desenvolvimento de políticas públicas no Brasil (Fauré, 2005; Machado, Cotta, \& Soares, 2015). A interrupção de projetos apresenta consequências negativas como o desperdício de recursos públicos, a perda de saberes institucionais, o desânimo das equipes envolvidas. Com a interrupção da PNSR, o Brasil passou os próximos 30 anos sem um planejamento relacionado ao abastecimento de água e esgotamento sanitário em áreas rurais na esfera federal. Essa situação foi alterada apenas em 2019, com a publicação do Programa Nacional de Água e Saneamento Rural (FUNASA, 2019)

Com o objetivo de se compreender as motivações para a elaboração de um projeto nacional de saneamento rural, no âmbito da conjuntura política, econômica, social e institucional do Brasil, em meados da década de 1980, são analisadas neste artigo as circunstâncias que culminaram na abertura da janela de oportunidades para a ascensão do PNSR à agenda governamental.

Diferentes modelos teóricos buscam explicar as relações complexas e as diversas variáveis que constituem o processo político pelo qual emergem as políticas públicas. No presente artigo aborda-se a primeira etapa desse processo, que consiste na montagem da agenda. É nessa fase que os problemas tornam-se alvo de atenção do governo. Isso não garante que o problema será resolvido pelo governo, mas que estará em evidência em meio a um conjunto de problemas existentes em uma sociedade em determinado momento (Howllet \& Ramesh, 2013).

Adota-se como base teórica o Modelo de Múltiplos Fluxos (Kingdon, 1995). Esse modelo tornou-se uma referência para os estudos voltados à análise da formulação de políticas governamentais, sendo aplicado em diversas áreas (Jones et al., 2016), incluindo a saúde (Mannheimer, Lehto, \& Ostlin, 2007; Mauti et al., 2019) e a gestão das águas (Font \& Subirats, 2010; Smith, Porter, \& Upham, 2016). Também se observa sua utilização em diferentes contextos, desde pesquisas na esfera local (Liu, Lindquist, Vedlitz, \& Vincent, 2010) até estudos de formação de agenda multilateral (Sumida, 2017).

Embora tenha sido desenvolvido no contexto dos EUA para a análise de políticas de saúde e transporte, o Modelo de Fluxos Múltiplos tem sido amplamente aplicado para analisar estudos de caso no contexto brasileiro (Costa \& Rezende, 2016, Eça, Fracalanza, \& Jacobi, 2011; Ferreira, 2013). Também foi abordado em análises teóricas que realizam uma interpretação crítica desse modelo, suas características e possíveis aplicações (Capella 2006; Capella, Brasil, \& Sudano, 2015; Gottems, Pires, Calmon, \& Alves, 2013). Esses estudos geralmente enfatizam a flexibilidade do método e atestam que a articulação entre a definição do problema, a definição de alternativas e o processo político, proposta por Kingdon (1995), é produtiva para explicar as inovações na agenda pública. No entanto, enfatizam a importância de se aplicar o modelo levando em consideração a realidade local a ser analisada e seu contexto histórico.

As variáveis amplas propostas por Kingdon (1995) permitem elucidar a subjetividade do processo de tomada de decisão. Por isso, de acordo com Zahariadis (1998), trata-se de um método adequado para explicar como as agendas são definidas por governos nacionais sob condições de ambiguidade de objetivos ou em ambientes instáveis, nos quais as escolhas são dependentes do contexto. Acredita-se que essas características são coerentes com o período histórico do qual o PNSR fez parte, caracterizado pelo processo de redemocratização após 20 anos de ditadura militar no Brasil. 


\section{METODOLOGIA}

No Modelo de Múltiplos Fluxos três fluxos decisórios - problemas, soluções e política - seguem seu curso de maneira independente, até que uma situação crítica crie as condições necessárias à abertura de uma janela de oportunidades, que leva a mudanças na agenda (Kingdon, 1995).

No fluxo de problemas o modelo busca analisá-los de modo a interpretar a forma como são reconhecidos e por que apenas alguns deles, em meio a um amplo conjunto de problemas, passam a ocupar a agenda governamental. Esse processo pode ocorrer por meio de três mecanismos: indicadores de monitoramento; eventos e situações de crises; e feedback das ações governamentais (Kingdon, 1995).

No segundo fluxo, o das soluções ou alternativas, a questão central consiste em se conhecer como são geradas as ideias capazes de prover soluções a determinados problemas. As alternativas são geradas por comunidades compostas por especialistas, governamentais ou não, os quais compartilham uma preocupação em relação a uma área de interesse. Ideias surgem, combinam-se, recombinam-se e no cerne dessa dinâmica algumas delas desaparecem, enquanto outras sobrevivem e prosperam (Kingdon, 1995).

O terceiro fluxo é composto pela dimensão política e envolve os acontecimentos políticos, considerados poderosos formadores de agenda. Independente do reconhecimento de um problema ou das alternativas disponíveis, o fluxo político segue sua própria dinâmica e regras (Kingdon, 1995).

Procedeu-se, então, o mapeamento dos três fluxos propostos por Kingdon (1995) a partir dos contextos político, econômico, social e institucional vivenciados no Brasil na década de 1980, buscando-se associá-los à formulação do PNSR. Em seguida, analisou-se a combinação dos três fluxos, proporcionando a abertura da janela de oportunidades que possibilitou a inserção do saneamento rural no conjunto das políticas governamentais.

A base empírica para a pesquisa foram as entrevistas realizadas pela primeira autora e consulta a dados documentais. Os documentos analisados consistem em: documentos públicos oficiais, decorrentes dos estudos para a elaboração do PNSR, disponíveis nas bibliotecas do IPEA e Copasa (IPEA 1989a, 1989b, 1989c); documentos referentes ao desenvolvimento do Projeto-Piloto (Dias, 1994; Ennes, 1990); e documentos legais (Brasil, 1985; IPEA, 1985; Portaria Interministerial N. 55, de 19 de dezembro de 1984; Portaria Interministerial N. 30, de 28 de fevereiro de 1985). Foi adotada a análise de conteúdo (Bardin, 2011) para a análise das entrevistas realizadas e documentos acessados.

O material verbal foi proveniente de 14 entrevistas semiestruturadas (Flick, 2011) com atores-chave que participaram da formulação do PNSR na esfera federal ou na implementação do Projeto-Piloto no estado de Minas Gerais. De forma a manter o anonimato dos participantes da pesquisa são utilizados os seguintes códigos para identificação dos entrevistados: IP: técnicos do IPEA, MS: técnicos do Ministério da Saúde, MDU: técnicos do Ministério do Desenvolvimento Urbano e Meio Ambiente, COP: técnicos da COPASA e OP: consultores contratados pela OPAS. O presente estudo foi aprovado pelo Comitê de Ética em Pesquisa da Universidade Federal de Minas Gerais (CAE 88462318.6.0000.5149). 


\section{RESULTADOS E DISCUSSÃO}

\subsection{0 fluxo de problemas}

As baixas condições de acesso dos habitantes das áreas rurais aos serviços de saneamento básico, a alta incidência de doenças infecciosas e parasitárias e as emigrações das populações do campo para as grandes cidades podem ser apontadas como grandes problemas nacionais que estiveram associados à formulação do PNSR.

A situação sanitária vivenciada nas áreas rurais do País caracterizava-se pela ausência de atendimento adequado. Segundo dados do Censo Demográfico de 1980 (IBGE, 1981), 83\% dos habitantes das áreas rurais não possuíam acesso à canalização interna de abastecimento de água e $62 \%$ destinavam suas águas residuárias a céu aberto ou diretamente no ambiente. Um entrevistado mencionou a 'cobertura muito baixa [de atendimento por serviços de saneamento] à época. (...) O Planasa ${ }^{1}$ não tinha proposta para a área rural. Então [o PNSR] veio complementar a ação do Planasa' (MS01).

De fato, o Planasa representou um marco para o saneamento no Brasil, pela magnitude das ações empreendidas, com amplos investimentos econômicos. Entretanto, ampliaram-se as diferenças entre áreas urbanas e rurais, no que tange à atuação do poder público, com uma distribuição desigual do acesso (Saiani \& Toneto, 2010).

Essa situação sanitária das áreas rurais certamente esteve associada ao quadro de saúde pública, em um período com elevada ocorrência de doenças infecciosas e parasitárias, como a esquistossomose, a ancilostomíase, a malária e a doença de Chagas. Na interpretação de um dos entrevistados, a mobilização em torno de uma agenda para o saneamento rural 'tem a ver um pouco também com a questão de saúde. As doenças que aconteciam, sobretudo na área rural, a carência e os agravos, isso também deve ter pesado na decisão. Em um contexto que era bem favorável, em 1986 o movimento sanitarista era muito forte' (OP03).

Essas enfermidades, que incidiam preponderantemente sobre as populações que habitavam as áreas rurais, tornaram-se mais presentes também nas áreas urbanas (Paim, Travassos, Almeida, Bahia, \& Macinko, 2011). Com o contexto de globalização, reformas e após uma crise econômica vivenciada na década de 1980, ocorre no Brasil um novo impulso às emigrações da população rural para as áreas urbanas (Perz, 2000). Uma entrevistada salienta a relevância do desenvolvimento de uma política de saneamento com o intuito de 'segurar o homem no campo. O Brasil estava em expansão urbana aceleradíssima. Isso era algo que nós colocávamos em todas as nossas publicações na época. Um dos ganhos [do PPNSR] era isso, (...) segurar as pessoas ali' (COP05).

Após um período de industrialização, durante as décadas de 1950 a 1970, ocorreram no Brasil diversas transformações nas esferas política, econômica e social que repercutiram na dinâmica demográfica, afetando os padrões migratórios e de morbi-mortalidade, resultando no aumento das

\footnotetext{
${ }^{1}$ Plano Nacional de Saneamento - Planasa, instituído em 1971. O Planasa foi capaz de elevar os índices brasileiros de cobertura de serviços de abastecimento de água e, em menor grau, de esgotamento sanitário. Contudo, priorizava a atuação em áreas urbanas, privilegiandose as regiões de economia mais dinâmica do país. Assim, o Plano promoveu o aumento das desigualdades em termos de condições sanitárias, uma vez que a parcela da população com menor poder econômico e fraca representação política não foi contemplada pelos avanços alcançados (Britto et al., 2012). Com a crise econômica vivenciada no País nos anos 1980 tem-se o declínio do Planasa e um vazio institucional no setor.
} 
demandas relacionadas aos setores de saúde e saneamento (Cunha, 2005). Nos centros urbanos, devido à falta de um planejamento adequado, tem-se a geração de aglomerados populacionais desordenados, com baixa provisão de infraestrutura e qualidade de vida. Dessa forma, ações capazes de proporcionar a contenção dos emigrantes rurais em seu lugar de origem eram estimuladas.

No fluxo de problemas, Kingdon (1995) afirma que quando os indicadores apontam para a existência de uma questão, esta pode ser percebida como um problema pelos formuladores de políticas públicas, despertando sua necessidade de ação. O Brasil das décadas de 1970 e 1980 apresentava indicadores sanitários e socioeconômicos alarmantes. A publicação das estatísticas de mortalidade do Brasil em 1980, pelo Ministério da Saúde, apontava a alta incidência de óbitos por doenças infecciosas e parasitárias, especialmente em menores de um ano e em crianças de 1 a 4 anos (Barros, 1984). Especificamente no que se refere às Doenças Relacionadas ao Saneamento Ambiental Inadequado (DRSAI), a taxa de mortalidade no Brasil era de 30 óbitos para cada 100 mil habitantes. Nas macrorregiões com menores porcentagens de atendimento por serviços de saneamento, como Norte e Nordeste, esse índice atingia 48 e 39 óbitos para cada 100 mil habitantes, respectivamente (FUNASA, 2010).

Esse contexto da saúde pública brasileira revelava um quadro de carências no País. É nesta conjuntura de crise sanitária, e a partir dos problemas expostos, que começa a ser identificada a necessidade de reformulação do subsetor de saneamento rural e de desenvolvimento de uma política nacional. Após a realização de estudos no Brasil, em 1983, o Banco Mundial entregou ao Governo Federal o relatório "Study of selected water and wastes sector issues: rural water supply and sanitation". Como uma das recomendações desse documento se postulava que o BIRD considerasse a possibilidade de contribuir para o desenvolvimento do saneamento rural no Brasil. A partir de então, originou-se uma solicitação do Banco Nacional da Habitação (BNH) à SEPLAN para que fosse dada prioridade à promoção de um trabalho nessa área (IPEA, 1985).

Assim, como relatado por um dos entrevistados, iniciaram-se os estudos no IPEA e, futuramente, em 1985, as negociações que dariam início ao PNSR: 'O Ottani [coordenador do PNSR pelo IPEA] foi para Washington negociar o empréstimo com o Banco Mundial. Havia um documento, tipo um diagnóstico, da situação de saneamento no Brasil. Particularmente sobre o saneamento rural. E mostrava o contraste com o saneamento urbano, a desassistência das áreas rurais... (...) E baseado nesse documento o Governo Federal, através do IPEA, Ministério da Saúde e Ministério do Desenvolvimento Urbano resolveram levar a frente um projeto' (OP01).

\subsection{0 fluxo de soluções}

Segundo Kingdon (1995), o fluxo de alternativas e soluções pode ser construído gradualmente por meio de um processo de debates, audiências, projetos de lei etc. Em meados dos anos 1970 ganhava expressão cada vez maior no Brasil o debate envolvendo as questões de saúde. Nessa época desencadeia-se o movimento pela reforma sanitária brasileira, que procurava superar os limites rígidos impostos pelo regime autoritário e introduzir mudanças progressivas nas bases da organização do sistema de saúde do País. No encalço desse movimento, apoiadas na visão da saúde como um direito, surgem diversas propostas de mudanças políticas e estruturais no Brasil.

Ressalta-se também a ocorrência de intensas atividades de veiculação de ideias e aglutinação de pensamento crítico em saúde e a organização de inúmeras conferências e debates. Destaca-se aqui a 
VIII Conferência Nacional de Saúde (CNS), ocorrida em 1986. O relatório da referida conferência contém um conjunto de políticas articuladas, reivindicadas pelo movimento sanitarista, tendo subsidiado a elaboração do capítulo relativo à saúde na Constituição de 1988. O movimento pela reforma sanitária também se fez presente na conjuntura pós-1988, quando se desenvolveu o processo de construção do Sistema Único de Saúde (SUS) consolidando-se princípios da Constituinte, como equidade, integralidade e universalidade (Paiva \& Teixeira, 2014). Além disso, como salientado por Paiva (2016), a agenda do saneamento rural, levantada como bandeira por organismos internacionais como a OPAS e por diferentes atores e movimentos sanitaristas nacionais, não era pauta absolutamente nova no quadro das políticas de saúde no País.

Esse momento histórico para o campo da saúde pública trouxe inovações e questionamentos que influenciavam os atores governamentais envolvidos na formulação do PNSR, em um contexto de abertura política e redemocratização, destacado por um entrevistado, que relata 'um clima muito favorável para se entender um pouco mais sobre as necessidades das populações mais pobres, mais desassistidas. A área de saúde, as Conferências Nacionais de Saúde, influenciaram muito [a elaboração do PNSR]' (MDU01). Nesse contexto, a necessidade de reconstrução de um novo modelo político e social refletiu nos princípios trazidos pelo PNSR, pois se tratava de 'uma época em que a população estava vivenciando a democracia. Muitas vertentes democráticas participaram do governo. E foi muito importante isso, porque essas convicções vão aparecer no texto [da Série Saneamento Rural]' (MDU01).

Com um ambiente favorável, de efervescentes discussões, necessitava-se de um aparato institucional para a operacionalização de um projeto nacional de saneamento rural, além de recursos técnicos e financeiros que permitissem sua viabilização. A elaboração do PNSR foi conduzida pelo IPEA, vinculado à SEPLAN. Um fator importante a ser considerado na análise do período em estudo consiste na ocupação dos espaços institucionais por técnicos que não reproduziam a política dominante - pelo contrário, utilizavam esses espaços para defender propostas alternativas, contra-hegemônicas (Escorel, 1999). Embora a coordenação do PNSR pelo IPEA, fosse conduzida por um economista neoclássico, o que poderia gerar certas críticas, a liberdade de discussão de ideias é ressaltada por um dos consultores da OPAS: 'tivemos liberdade [na formulação do PNSR]. Nosso coordenador era meio rígido, ele ficava sempre tentando enquadrar a gente, mas pelo menos em nível de discussão, podia-se discutir sobre tudo!' (OP02).

Ainda no contexto institucional de formulação do PNSR, tem-se a participação da Fundação Serviço Especial de Saúde Pública (FSESP), instituição com atuação já consolidada no País. Uma característica desta instituição, desde a sua origem, é a proximidade com os poderes locais, apresentando capilaridade em todo o território brasileiro. Essa vocação foi realçada por um entrevistado ligado ao Ministério da Saúde: 'A FSESP entrou [na formulação do PNSR] pela experiência rural. Ela tinha unidades de saúde e junto tinha as oficinas de saneamento, que trabalhava junto com a comunidade pra fazer as melhorias sanitárias domiciliares, fazer fossas, já trabalhava muito nessa linha' (MS01).

Embora o órgão apresentasse forte caráter tecnicista e, por vezes, autoritário, tem-se uma instituição reconhecida e com anos de experiência e atuação no território nacional, especialmente em localidades de pequeno porte populacional e áreas rurais, constituindo um ambiente propício para o suporte ao desenvolvimento de projetos de saneamento rural dentro de uma conjuntura de intensos debates no setor de saúde. 
Por fim, a parceria com organismos internacionais proporcionou os apoios técnico e financeiro necessários para o fomento ao PNSR. Tecnicamente, o referido Projeto contava com o apoio da OPAS, entidade que expandia a sua atuação e já possuía parcerias com o governo brasileiro na formação de trabalhadores para a saúde (Paiva, Pires-Alves, \& Hochman, 2008). Desde a década de 1960, após a difusão do planejamento em saúde pela Comissão Econômica para a América Latina e o Caribe (CEPAL), a OPAS ficou encarregada de assessorar os países que receberam recursos de agências financiadoras internacionais na elaboração de suas políticas, bem como avaliar os projetos elaborados com o intuito de se alcançarem as metas pré-estabelecidas (Giovanella, 1991).

O período de 1981 a 1990 foi considerado pela Organização das Nações Unidas (ONU) a "Década Internacional de Água Potável e Esgotamento Sanitário". Nesse período, o saneamento - e, numa perspectiva mais ampla, a saúde ambiental - foi uma das áreas mais importantes de atuação da OPAS, estabelecendo-se como prioridade o alcance das metas de saneamento e saúde ambiental na América Latina. Observam-se a consolidação da engenharia sanitária na instituição e a realização de diversas iniciativas de cooperação técnica nessa área (Lima, 2002). Assim, a instituição agregou ao PNSR a experiência adquirida na formulação de políticas voltadas para comunidades rurais em países da América Latina, conforme evidenciado por um entrevistado: '[O PNSR] era um projeto de diversos atores (...) e houve uma negociação para se trazer a Organização Mundial de Saúde. A parte técnica do Projeto foi toda desenvolvida pelo pessoal da OPAS, que trouxe a experiência em trabalhos comunitários. O pessoal já tinha uma certa experiência em países da América Latina. E assim fizemos um acordo de cooperação' (IP01).

A elaboração do PNSR foi financiada pelo BIRD, ganhando destaque, durante a década de 1980, o envolvimento do Banco Mundial em assuntos econômicos e políticos de países da América Latina (Vilas, 2015). Até então o Banco havia se limitado a financiar projetos de investimento, mas a partir dos anos 1980, além de sua função original, o Banco Mundial passou a recomendar e supervisionar as políticas públicas dos países afetados pela crise internacional. A influência exercida pelo BIRD sobre o PNSR é percebida de maneira diferente por alguns entrevistados. Um entrevistado ressalta o papel de monitoramento: 'vinha gente do Banco para as reuniões de acompanhamento, lógico que da área de saneamento, que já tinha conhecimento de atuações no mundo inteiro, mas não influenciavam no conteúdo do Projeto' (MDU01). Outro entrevistado, por sua vez, enfatiza as sugestões técnicas oferecidas: 'como o Banco Mundial tinha experiência internacional realmente notável, ele aproveitou isso. Lembro de sugestão de tecnologias apropriadas, várias alternativas de sistemas simplificados baseados em experiências em outros países. Então tinha essa influência, sim. Mas não exigiam, não havia indução' (OP01).

Tem-se assim a conjuntura social e institucional que compõe o fluxo de soluções, culminando na elaboração do PNSR. Nacionalmente, trata-se de um momento de intensos debates, especialmente no setor de saúde, propício ao surgimento e elaboração de pautas associadas, como o saneamento rural, que já se encontrava presente e era foco de atuação das instituições envolvidas, como o IPEA e a FSESP. Internacionalmente, as experiências da OPAS e do BIRD, envolvendo trabalhos sobre saneamento básico em comunidades rurais na América Latina e no mundo, proporcionaram um arcabouço teórico e empírico mais amplo, que foi discutido e adaptado para a realidade brasileira durante a formulação do PNSR. 


\subsection{0 fluxo da dinâmica política}

De acordo com Kingdon (1995), é o fluxo da dinâmica política que determina a relevância de um tema para a agenda governamental, independente dos outros dois fluxos (problemas e soluções), uma vez que o fluxo político apresenta regras próprias. Esse fluxo é influenciado por processos como o humor nacional, formação de coalizões e grupos de interesse e mudanças no governo. Kingdon (1995) também destaca o processo eleitoral como um dos fatores predominantes no estabelecimento da agenda.

O contexto político brasileiro da década de 1980 caracteriza-se pela instabilidade e ocorrência de alterações profundas. Tem-se neste período uma mudança de conjuntura decorrente do fim da ditadura militar (1964-1984), eleição indireta de um governo civil (o Governo Sarney, 1985-1989) e, posteriormente, a eleição direta de Fernando Collor (1990-1992) para a Presidência da República. O contexto anterior, dos governos militares, provocou fortes influências na dinâmica política do período em estudo, não podendo ser ignorado.

Enquanto no contexto econômico vivenciava-se a passagem de um período desenvolvimentista e de elevado crescimento econômico, durante a década de 1970, para um momento de crise e recessão, durante a década de 1980; no contexto político experimentava-se o processo lento e gradual de abertura política; e no contexto social, ampliava-se o fortalecimento dos movimentos populares e da organização política. A crise que sucedeu o milagre econômico acentuou o descontentamento com o regime militar, alvo de profundas críticas e acusado, particularmente, de ter acentuado as desigualdades regionais e sociais, com o aumento da concentração de renda entre os mais ricos. Embora o País tenha alcançado um crescimento econômico próximo dos $10 \%$ ao ano, o regime militar não foi capaz de reduzir as injustiças sociais, ao contrário, observou-se um processo de concentração econômica, alta da inflação e aumento da dívida externa que prenunciava uma crise social bem mais ampla (Silva, 1990). Assim, a partir de meados da década de 1970, o Brasil passou por um intenso movimento popular pela reforma das políticas sociais, dentre elas a de saúde.

A luta pela redemocratização adquiriu novas características e estratégias. Antes restrita às universidades, aos grupos clandestinos e aos movimentos sociais, cada vez mais passou a ser localizada no interior do próprio Estado. Em 1982, quando ocorreram as primeiras eleições livres para o Congresso e Assembleias Legislativas em 20 anos, foram eleitos deputados, prefeitos e vereadores que tinham a temática da saúde em suas plataformas eleitorais e apresentavam ligações de forma mais geral com a questão da democratização (Fleury, 2009; Luz, 1991; Menicucci \& D’Albuquerque, 2018). De acordo com Escorel (2005), o movimento sanitarista também apresentou forte atuação dentro da esfera governamental a partir dos seus técnicos, contribuindo assim para a realização de reformas na política vigente: 'muitas coisas que conseguiram ser viabilizadas, foram porque pessoas ligadas a esse movimento [sanitarista] eram contratadas como técnicas, pelo seu currículo, sua capacidade técnica. E conseguiam, dentro dessas instituições, promover pequenas mudanças'.

No caso do PNSR, um consultor ligado à OPAS ressalta como o momento político vivenciado no Brasil influenciou os técnicos envolvidos a trazerem seus ideais para a condução do Projeto: 'Muita coisa que ficava engasgada na garganta da gente por muito tempo e ficaram meio adormecidas, o PNSR pôde ser uma válvula pra colocarmos muitos dos ideais que sempre existiram - antes, durante e após 
o regime militar - mas que ficaram mais escondidos. (...) E muitos dos que estavam ali, inclusive eu, tínhamos esse envolvimento com movimento estudantil, com a VIII CNS, que foi um marco, com as ideias de Paulo Freire, que eram dessa época...' (OP02).

Toda esta efervescência democrática foi canalizada para os trabalhos da Assembleia Nacional Constituinte, resultando na promulgação, em 1988, da nova constituição brasileira, a qual avançou em relação às formulações legais anteriores, garantindo aos brasileiros um amplo conjunto de direitos sociais.

No Governo do Presidente José Sarney, as mudanças promovidas foram caracterizadas pela crítica à centralização institucional e financeira do sistema herdado dos governos militares. No início deste Governo, os diversos planos de ação governamental instituídos priorizaram o resgate da "dívida social", rejeitando a sujeição das políticas sociais às medidas de ajuste macroeconômico. O slogan do início do Governo Sarney era “Tudo pelo social”. No biênio 1985-1986, a instituição de grupos de trabalho e comissões setoriais foi um dos principais impulsos reformistas do executivo federal (Risi \& Nogueira, 2002). Logo, a instituição de um Comitê Interministerial de Saneamento Rural para a formulação do PNSR condiz com a lógica de condução do Governo Federal instaurada naquele momento. Entretanto, na medida em que a situação econômica do País se deteriorava, as pretensas políticas sociais e democráticas foram progressivamente substituídas, na segunda fase do Governo Sarney, por propostas conservadoras e autoritárias (Escorel, 1999). O PNSR emerge em meio a essa dinâmica política.

Cabe mencionar que no contexto internacional, nessa época, ganhava força o ideário neoliberal, balizado por organismos multilaterais, como o Banco Mundial e o FMI, pressionando os governos dos países da periferia a um programa político baseado na liberalização comercial, na desregulação financeira, na desregulamentação ampla da economia e na privatização de empresas públicas, como um modelo de desenvolvimento supostamente válido para todas as sociedades (Pereira, 2015).

\subsection{A janela de oportunidades}

No Modelo de Múltiplos Fluxos o momento em que ocorre a convergência entre os três fluxos é denominado por Kingdon (1995) como acoplamento. Nesse momento, um problema é reconhecido, uma solução está disponível e as condições políticas tornam a ocasião propícia para a mudança, possibilitando que questões ascendam à agenda. As circunstâncias que possibilitam a convergência dos fluxos, denominadas janela de oportunidades, são influenciadas, sobretudo, pelo fluxo de problemas e pelo fluxo político. Como ressaltado por Kingdon (1995), o fluxo de soluções não exerce influência direta sobre a oportunidade de mudança da agenda, uma vez que as propostas, alternativas e soluções elaboradas chegam à agenda apenas quando os problemas percebidos, ou as demandas políticas, criam oportunidades para essas ideias.

Um importante ator que contribui para a integração dos fluxos consiste no empreendedor de políticas. Quando a janela se abre, esses indivíduos, que podem ou não fazer parte do governo, desempenham um papel fundamental, unindo soluções a problemas; propostas a momentos políticos; e eventos políticos a problemas (Kingdon, 1995).

No caso em estudo, conforme discutido nos itens anteriores, os problemas existentes nas áreas rurais do Brasil, relacionados às migrações das populações do campo para as cidades, à falta de acesso 
adequado às soluções de saneamento básico e à alta incidência de doenças infecciosas e parasitárias eram perceptíveis ao se analisar alguns indicadores da época. Esses problemas despertam a atenção governamental a partir de um relatório elaborado pelo Banco Mundial, fazendo com que o governo brasileiro priorizasse a realização de estudos e diagnósticos nesta área com o intuito de, futuramente, negociar um empréstimo junto ao BIRD. Socialmente vivia-se uma época de efervescência intelectual e reorganização de movimentos sociais que influenciavam as ideias de técnicos governamentais, dentre eles os envolvidos na elaboração do PNSR. Concomitantemente a esses fatores, no fluxo da dinâmica política nacional, se tem um momento propício para a discussão de políticas sociais, tendo o setor de saúde alcançado grande relevância no contexto da reformulação da democracia brasileira. Essa era a configuração dos fluxos, na segunda metade da década de 1980, que seguiam seus caminhos de forma independente.

A convergência dos fluxos foi propiciada por uma solicitação do governo do Rio Grande Sul junto ao BNH para captação de recursos externos, via BIRD, para investimentos em saneamento básico nas comunidades rurais do estado. O projeto elaborado pelo governo estadual foi submetido à avaliação do IPEA, órgão de planejamento do governo federal. Em seu parecer, um técnico do setor de saneamento do IPEA recusou a continuidade do projeto, alegando a ausência de ações de educação e participação social, o que prejudicaria a efetividade das ações a serem implementadas. Em decorrência dessa decisão iniciaram-se as discussões que resultariam no desenvolvimento do PNSR, conforme relato: 'Eu resolvi pesquisar sobre o assunto e fiz um parecer contrário, por causa da questão de educação da comunidade que precisaria ser melhor estudada. Isso deu um rolo. Veio pessoal do Banco Mundial, BNH, vice-presidente do IPEA... Eu comentei que essa questão sanitária necessitava de uma abordagem diferente, o projeto precisaria de um novo arranjo. A partir daí foram várias conversas. (...) Resumindo: concordaram em desenvolver um projeto nacional que o IPEA iria coordenar, envolvendo também a FSESP, financiado pelo Banco. Nós não esperávamos. Não era essa a intenção inicial. Mas foi a solução que encontraram e assim se iniciou o projeto' (IP02).

Em decorrência dessas negociações foi assinado, em maio de 1985, o acordo de empréstimo 2532-BR para o "Projeto-piloto e de assistência técnica para abastecimento de água e tratamento de dejetos nas áreas rurais", objeto de financiamento pelo BIRD à República Federativa do Brasil. E iniciou-se a formação da equipe para a condução do Componente Nacional do Projeto, a partir da instituição de um comitê interministerial, em dezembro de 1984. O Rio Grande do Sul ficou responsável pela realização do Projeto-Piloto do PNSR, sendo substituído por Minas Gerais, em 1987, devido ao endividamento do estado.

Observa-se, portanto, a atuação de IP02 como um importante empreendedor de políticas. Ao questionar a proposta inicial de investimento em ações de saneamento rural em um estado brasileiro, involuntariamente, o técnico governamental contribuiu para o início de um processo que resultaria, após diversas negociações entre os atores envolvidos, na junção dos três fluxos, promovendo a consciência da necessidade de um planejamento nacional para a execução de ações de saneamento básico nas áreas rurais do Brasil. Nesse momento, diante dos problemas nacionalmente conhecidos, da dinâmica política favorável e da disponibilidade de solução a partir do desenvolvimento de um projeto na esfera federal conduzido pelo IPEA e financiado com recursos do BIRD, a temática do saneamento rural emerge à agenda pública. A Figura 1 apresenta uma síntese da configuração dos três fluxos, revelando os processos que resultaram na abertura da janela de oportunidade. 
RAP | A entrada na agenda brasileira do Projeto Nacional de Saneamento Rural (1985)
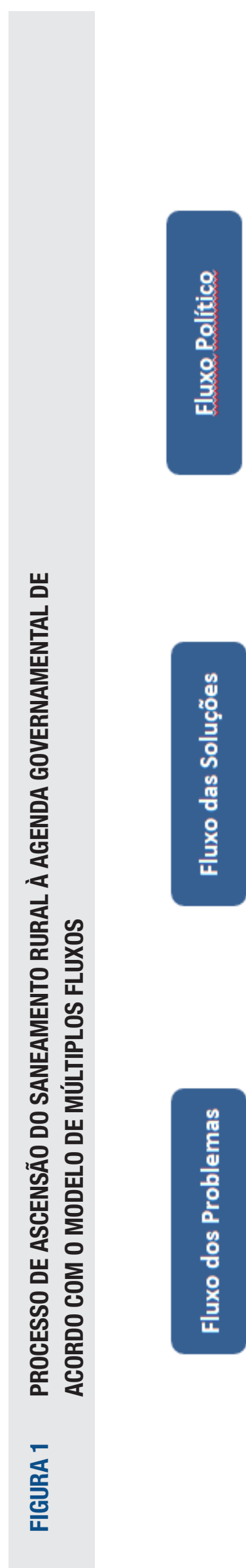

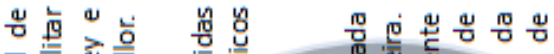

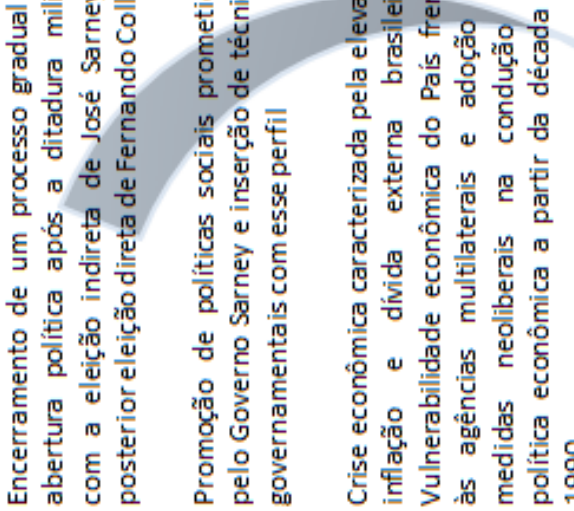

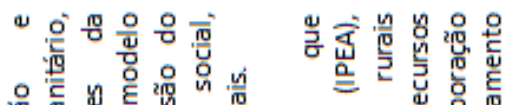

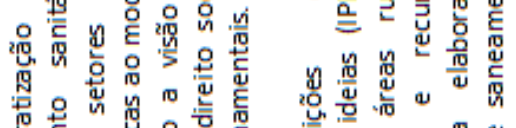

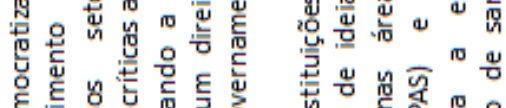

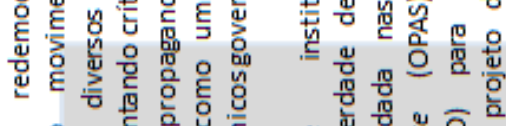

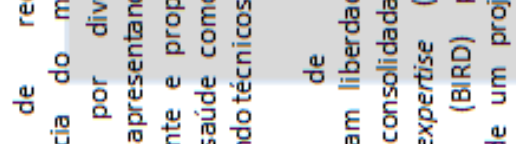

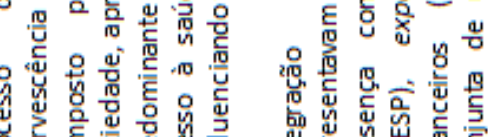

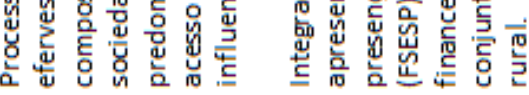

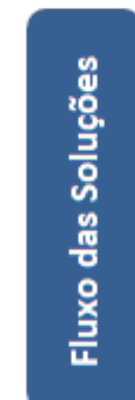
.<smiles>[CH]1CC1</smiles>

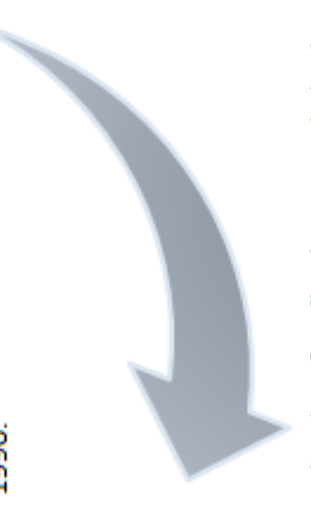

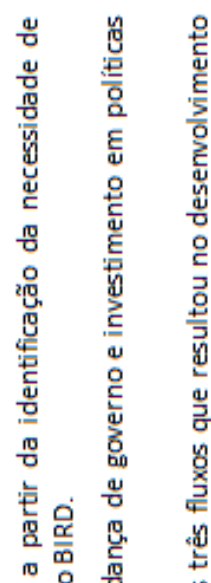

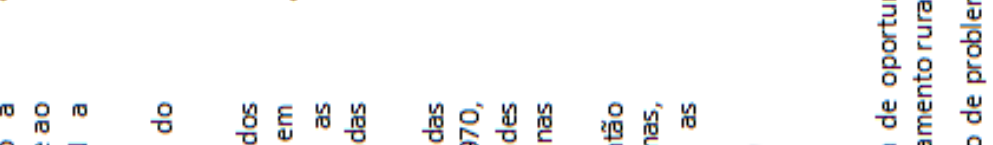

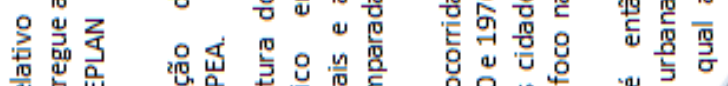

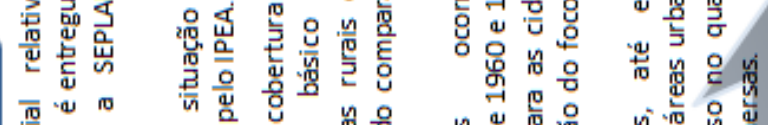

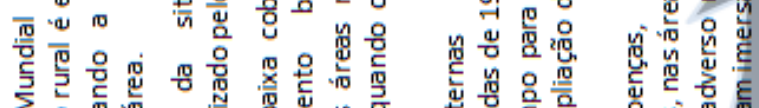

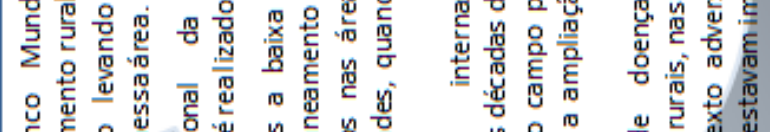

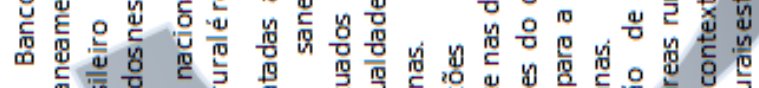

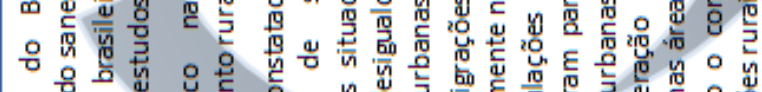
응해

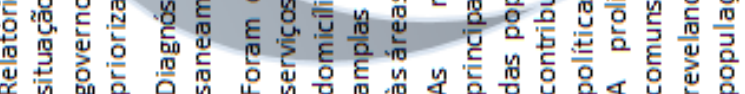

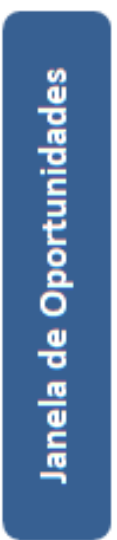

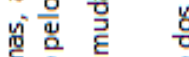

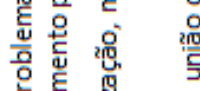




\section{CONCLUSÕES}

O presente artigo apresenta como objetivo analisar as circunstâncias que culminaram na abertura de janela de oportunidades para entrada do Projeto Nacional de Saneamento Rural na agenda governamental. A partir das análises realizadas encontram-se evidências de que a ascensão do saneamento rural à agenda ocorreu em decorrência de uma época de intensas transições vivenciadas no Brasil. A partir do fluxo de problemas - baixa cobertura nas áreas rurais com serviços de saneamento básico, alta incidência de doenças, migrações da população do campo - se desperta a necessidade de maior atuação e desenvolvimento de estudos para execução de ações de saneamento básico nas áreas rurais, especialmente após relatório do Banco Mundial apresentado ao governo brasileiro indicando a premência de desenvolvimento do subsetor.

O fluxo político também se mostra importante para a condução do PNSR à agenda governamental, com a eleição indireta de José Sarney, em 1985, durante a qual é fomentada a elaboração de políticas sociais. A busca da garantia de direitos sociais no processo de redemocratização brasileiro, no contexto político e a atuação de fortes movimentos sociais, dentre eles o movimento sanitarista, no contexto social, impactam, direta ou indiretamente, os técnicos governamentais responsáveis pela elaboração do Projeto.

No fluxo de soluções, o envolvimento conjunto de instituições com expertise, como o IPEA, a FSESP e a OPAS, e a disponibilidade de recursos financeiros, provenientes de parceria com o BIRD, proporcionaram um ambiente favorável para a condução do Projeto. A junção dos três fluxos e a consequente abertura da janela de oportunidades é promovida pela atuação de um empreendedor de políticas que, involuntariamente, contribuiu para o processo de negociações que resultariam na formulação do PNSR.

O Modelo de Múltiplos Fluxos, utilizado como referencial teórico para a condução do estudo, se mostrou adequado para a compreensão do tema, auxiliando na detecção dos fatores relacionados à entrada na agenda do saneamento rural, resultando na elaboração do PNSR. Ressalta-se que as instituições representaram um importante papel na ascensão do objeto de estudo à agenda governamental. Embora esses atores não sejam diretamente abordados no modelo original publicado por Kingdon, isso não impediu que fossem inseridos na análise, graças ao caráter fluido da teoria. Dessa forma, acredita-se que o Modelo de Múltiplos Fluxos proporciona flexibilidade à análise da formação de agendas públicas e auxilia na construção da macro conjuntura vivenciada, sendo aplicável em diferentes contextos e realidades.

Após o acesso à agenda governamental, a implementação da PNSR foi prejudicada. Fatores como a crise econômica do Brasil, a consequente recessão e a incapacidade do governo de financiar políticas públicas podem ter afetado a continuidade do projeto. As mudanças políticas, com a eleição de Fernando Collor em 1990, e a reorganização institucional promovida pelo novo governo podem ter contribuído para a dissociação dos três fluxos e o fechamento da janela de oportunidades. Recomenda-se a realização de estudos que promovam uma exploração mais aprofundada dos motivos que resultaram na falha do PNSR, mapeando os principais fatores condicionantes de maneira mais precisa, o que contribuiria para o entendimento das descontinuidades políticas no setor de água e saneamento no Brasil. 


\section{REFERÊNCIAS}

Bardin, L. (2011). Análise de conteúdo (5a ed.) Lisboa, Portugal: Edições 70.

Barnes, R., Roser, D., \& Brown, P. (2011). Critical evaluation of planning frameworks for rural water and sanitation development projects. Development in Practice, 21(2), 168-189.

Barros, M. B. A. (1984). Considerações sobre a mortalidade no Brasil em 1980. Rev. Saúde Pública, 18(2), 122-137.

Brasil. (1985). Projeto de estudos, assistência técnica e reorganização institucional do subsetor de saneamento básico rural. Termos de Referência. Documento de trabalho, 05 de julho de 1985. Brasília, DF: Autor.

Capella, A. C. N. (2006). Perspectivas teóricas sobre o processo de formulação de políticas públicas. Revista Brasileira de Informação Bibliográfica em Ciências Sociais, 61, 25-52.

Capella, A. C. N., Brasil, F. G., \& Sudano, A. D. C. G. P. (2015). O estudo da agenda governamental: reflexões metodológicas e indicativos para pesquisas. In Anais do $39^{\circ}$ Encontro Anual da ANPOCS, Caxambu, MG.

Costa, O. S., Filho, \& Rezende, S. (2016). O saneamento na agenda pública: a dinâmica política e a implantação dos serviços em Rio Branco, Acre. Revista Brasileira de Gestão e Desenvolvimento Regional, 12(1), 331-354.

Cunha, J. M. P. (2005). Migração e urbanização no Brasil: alguns desafios metodológicos para análise. São Paulo Perspec., 19(4), 3-20.

Dias, M. G. (1994). Frutos mirrados. Revista Bio, 6(2), 7-10.

Eça, R. F., Fracalanza, A. P., \& Jacobi, P. R. (2013). A problemática da água na agenda governamental do estado de São Paulo (1920-1991). Revista Política Pública, 17(1), 49-58.

Ennes, Y. M. (1990, out./dez.). Contribuição à memória do saneamento rural em Minas: operacionalização e avaliação dos programas estaduais. Revista Bio, 50-55.

Escorel, S. (1999). Reviravolta na saúde: origem e articulação do movimento sanitário. Rio de Janeiro, RJ: Editora Fiocruz.
Escorel, S. (2005). Depoimento da médica sanitarista Sarah Escorel (ENSP/Fiocruz) fornecido em 14/04/2005 ao projeto 'Memória e Patrimônio da Saúde Pública no Brasil: a trajetória de Sérgio Arouca'. Rio de Janeiro, RJ: Programa de Pós-Graduação em Memória Social da Universidade Federal do Estado do Rio de Janeiro. Recuperado de http://www. memoriasocial.pro.br/linhas/arouca/depoimentos/ depoimentosarahescorel.htm

Fauré, Y. A. (2005). Des politiques publiques décentralisées, entraves au développement local: expériences brésiliennes. Revue Tiers Monde, 181(1), 95-118.

Ferreira, A. M. (2013). Projeto de transposição de águas do Rio São Fansicso: uma análise do processo de agenda-setting (Dissertação de Mestrado). Fundação Getúlio Vargas, São Paulo, SP.

Fleury, S. (2009). Reforma sanitária brasileira: dilemas entre o instituinte e o instituído. Ciência \& Saúde Coletiva, 14(3), 743-752.

Flick, U. (2011). Introdução à pesquisa qualitativa. Porto Alegre, RS: Artmed.

Font, N., \& Subirats, J. (2010). Water management in Spain: The role of policy entrepreneurs in shaping change. Ecology and Society, 15(2), 25-38.

Fundação Nacional de Saúde. (2010). Impactos na saúde e no sistema único de saúde decorrentes de agravos relacionados a um saneamento ambiental inadequado. Brasília, DF: Ministério da Saúde.

Fundação Nacional de Saúde. (2019). Programa Nacional de Saneamento Rural (PNSR). Brasília, DF: Ministério da Saúde. Recuperado de http:// www.funasa.gov.br/documents/20182/38564/ MNL_PNSR_2019.pdf/08d94216-fb09-468e-ac98afb4ed0483eb

Giovanella, L. (1991). As origens e as correntes atuais do enfoque estratégico em planejamento de saúde na América Latina. Cadernos de Saúde Pública, 7(1), 26-44.

Gottems, L. B. D., Pires, M. R. G. M., Calmon, P. C. D. P., \& Alves, E. D. (2013). O modelo dos múltiplos fluxos de Kingdon na análise de políticas de saúde: aplicabilidades, contribuições e limites. Saúde Soc., 22(2), 511-520.

Hall, P. A. (1993). Policy paradigms, social learning and the state: the case of economic policy making in Britain. Comparative Politics, 25(3), 275-296. 
Howllet, M., Ramesh, M., \& Perl, A. (2013). Política pública: seus ciclos e subsistemas: uma abordagem integral. Rio de Janeiro, RJ: Elsevier.

Instituto Brasileiro de Geografia e Estatística. (1981). Censo Demográfico 1980. Rio de Janeiro, RJ: Autor.

Instituto Brasileiro de Geografia e Estatística. (2011). Censo Demográfico 2010. Rio de Janeiro, RJ: Autor.

Instituto de Planejamento Econômico e Social. (1985). Nota Técnica n. 018, de 25 de março de 1985. Projeto Nacional de Saneamento Rural. Brasília, DF: Autor.

Instituto de Planejamento Econômico e Social. (1989a). Projeto Local de Saneamento Rural (Vol. 1, Série Saneamento Rural). Brasília, DF: Autor.

Instituto de Planejamento Econômico e Social. (1989b). Bases para formulação de políticas e programas em saneamento rural (Vol. 2 Série Saneamento Rural). Brasília, DF: Autor.

Instituto de Planejamento Econômico e Social. (1989c). Subsídios para elaboração de programas estaduais de saneamento rural (Vol. 3, Série Saneamento Rural). Brasília, DF: Autor.

Joint Monitorig Programme. (2019). Progress on household drinking water, sanitation and hygiene 2000-2017: special focus on inequalities. New York, NY: United Nations Children's Fund (UNICEF) and World Health Organization (WHO). Recuperado de https://washdata.org/sites/default/files/documents/ reports/2019-07/jmp-2019-wash-households.pdf

Jones, M. D., Peterson, H. L., Pierce, J. J., Herweg, N., Bernal, A., Raney, H. L. ... Zahariadis, N. (2016). A river runs through it: a Multiple Streams metareview. Policy Studies Journal, 44(1), 13-36.

Kingdon, J. W. (1995). Agendas, alternatives and publics policies (2a ed). New York, NY: Harper Collins.

Lei n. 11.445, de 5 de janeiro de 2007. (2007). Estabelece diretrizes nacionais para o saneamento básico; altera as Leis nos 6.766, de 19 de dezembro de 1979, 8.036, de 11 de maio de 1990, 8.666, de 21 de junho de 1993, 8.987, de 13 de fevereiro de 1995; revoga a Lei no 6.528, de 11 de maio de 1978; e dá outras providências. Brasília, DF. Recuperado de http://www.planalto.gov.br/ccivil_03/_ato20072010/2007/lei/l11445.htm
Lima, N. T. (2002). O Brasil e a Organização Pan-Americana da Saúde: uma história de três dimensões. In J. Finkelman. (Org.), Caminhos da saúde pública no Brasil (pp. 23-116). Rio de Janeiro, RJ: Fiocruz.

Liu, X., Lindquist, E., Vedlitz, A., \& Vincent, K. (2010). Understanding local policymaking: policy elites' perceptions of local agenda setting and alternative policy selection. Policy Studies Journal, 38(1), 69-91.

Luz, M. T. (1991). Notas sobre as políticas de saúde no Brasil de 'transição democrática': anos 1980. Physis: Revista de Saúde Coletiva, 1(1), 77-96.

Machado, J. C., Cotta, R. M. M., \& Soares, J. B. (2015). Reflexões sobre o processo de municipalização das políticas de saúde: a questão da descontinuidade político-administrativa. Interface - Comunicação, Saúde, Educação, 19(52), 159-170.

Mannheimer, L. N., Lehto, J., \& Ostlin, P. (2007). Window of opportunity for intersectoral health policy in Sweden: open, half-open or half-shut? Health Promotion International, 22(4), 307-315.

Mauti, J., Gautier, L., Neve, J. W., Beiersmann, C., Tosun, J., \& Jahn, A. (2019). Kenya's Health in All Policies strategy: a policy analysis using Kingdon's multiple streams. Health Research Policy and Systems, 17(15), 1-12.

Menicucci, T., \& D’Albuquerque, R. (2018). Política de saneamento vis-à-vis à política de saúde: encontros, desencontros e seus efeitos. In L. Heller. (Org.), Saneamento como política pública: um olhar a partir dos desafios do SUS (pp. 9-52). Rio de Janeiro, RJ: Fiocruz.

Paim, J., Travassos, C., Almeida, C., Bahia, L., \& Macinko, J. (2011). The Brazilian health system: history, advances, and challenges. Lancet, 377(9779), 1778-1797.

Paiva, C. H. A. (2016). O sertão na saúde e na formação de trabalhadores setoriais: contextos, atores e ideologias (1920-1970). Saúde em Debate, 40(110), 224-233.

Paiva, C. H. A., Pires-Alves, F., \& Hochman, G. (2008). A cooperação técnica OPAS-Brasil na formação de trabalhadores para a saúde (1973-1983). Ciência \& Saúde Coletiva, 13(3), 929-940. 
Paiva, C. H. A., \& Teixeira, L. A. (2014). Reforma sanitária e a criação do Sistema Único de Saúde: notas sobre contextos e autores. História, Ciências, Saúde - Manguinhos, 21(1), 15-35.

Pereira, J. M. (2015). Poder, política e dinheiro: a trajetória do Banco Mundial entre 1980 e 2013. In J. M. Pereira, \& M. Pronko. (Org.), A demolição de direitos: um exame das políticas do Banco Mundial para a educação e a saúde (1980-2013) (pp. 19-64). Rio de Janeiro, RJ: Fiocruz.

Perz, S. G. (2000). The rural exodus in the context of economic crisis, globalization and reform in Brazil. International Migration Review, 34(3), 842-881.

Portaria Interministerial N. 55, de 19 de dezembro de 1984. (1984). Brasília, DF: Secretaria de Planejamento da Presidência da República, Ministério do Interior e Ministério da Saúde.

Portaria Interministerial N. 30, de 28 de fevereiro de 1985. (1985). Brasília, DF: Secretaria de Planejamento da Presidência da República, Ministério do Interior e Ministério da Saúde.

Portaria N. 3.174, de 02 de dezembro de 2019. (2019). Dispõe sobre o Programa Nacional de Saneamento Rural e dá outras providências. Brasília, DF: Ministério da Saúde.

Rezende, S., \& Heller, L. (2008). O saneamento no Brasil: políticas e interfaces (2a ed.). Belo Horizonte, MG: Editora UFMG.
Risi, J. B., Jr., \& Nogueira, R. B. (2002). As condições de saúde no Brasil. In J. Finkelman (Org.), Caminhos da saúde pública no Brasil (pp. 117-234). Rio de Janeiro, RJ: Fiocruz.

Saiani, C. C. S., \& Toneto, R., Jr. (2010). Evolução do acesso a serviços de saneamento básico no Brasil (1970 a 2004). Economia e Sociedade, 19(1), 79-106.

Silva, F. C. T. (1990). A modernização autoritária: do golpe militar à redemocratização (1964/1984). In M. Y. Linhares (Org.), História geral do Brasil (4a ed., pp. 273-303). Rio de Janeiro, RJ: Editora Campus.

Smith, A., Porter, J. J., \& Upham, P. (2016). 'We cannot let this happen again': reversing UK flood policy in response to the Somerset Levels floods, 2014. Journal of Environmental Planning and Management, 60(2), 351-369.

Sumida, S. (2017). Agenda setting in multilateral contexts: the example of the Decade of Education for Sustainable Development. Globalisation, Societies and Education, 15(4), 381-396.

Vilas, C. M. (2015). O Banco Mundial e a reforma do Estado na América Latina: fundamentos teóricos e prescrições políticas. In J. M. Pereira, M. Pronko (Org.), A demolição de direitos: um exame das políticas do Banco Mundial para a educação e a saúde (1980-2013) (pp. 65-89). Rio de Janeiro, RJ: Fiocruz.

Zahariadis, N. (1998). Comparing three lenses of policy choice. Policy Studies Journal, 26(3), 434-448. 


\section{Nathalia Roland}

(1)

https://orcid.org/0000-0002-9823-6657

Doutoranda em Saneamento, Meio Ambiente e Recursos Hídricos na Universidade Federal de Minas Gerais.

E-mail: nathaliaroland@outlook.com

\section{Léo Heller}

https://orcid.org/0000-0003-0175-0180

Pesquisador no Instituto René Rachou. E-mail: leo.heller@fiocruz.br

\section{Sonaly Rezende}

https://orcid.org/0000-0002-5282-0938

Professora Associada no Departamento de Engenharia Sanitária e Ambiental e no Programa de Pós-Graduação em Saneamento, Meio Ambiente e Recursos Hídricos da Universidade Federal de Minas Gerais.

E-mail: srezende@desa.ufmg.br 